\title{
Experiences of Unemployed Black People Living with Disabilities in Soshanguve Township, South Africa - An Exploratory Study
}

\author{
Nomna Linda Jobodwana and Rendani Tshifhumulo*
}

\author{
University of Venda, South Africa
}

\begin{abstract}
The promise of a better life for all made by the South African government in 1994 remains unfulfilled, as many South Africans are still living in the margins of the economy where unemployment and poverty are rampant. People living with disabilities (PLWDs) are the worst affected, as they are poor with no access to jobs and housing. Despite the enactment of the Employment Equity Act (EEA) Number 55 of 1988, employment opportunities for black PLWDs are scarce in South Africa. This is due to, among other reasons, the fact that employers are reluctant to employ disabled people. This narrative study examined the experiences of black people living with disabilities (PLWDs) in Soshanguve Township, Tshwane, South Africa. It employed the symbolic interactionist (SI) theory as a lens to gain insights into the experiences of black women and men living with disabilities in their quest to access employment opportunities. The study was exploratory qualitative in nature and employed the case study design approach. Data were collected using a purposive sample of 15 black men and women living with disabilities in the Soshanguwe Township with whom in-depth interviews were conducted. This was complemented by focus group interviews with 13 purposively selected respondents who met the selection criteria. Findings were that people living with disabilities (PLWDs) were discriminated against and marginalised in employment and the workplace before and after post-apartheid South Africa. This situation leaves them inactive, economically disadvantaged and poor. The study expands knowledge on the experiences of black men and women who live with disabilities, thereby contributing towards the design of public policies and other social security interventions meant to alleviate the plight of marginalised communities in general and people living with disabilities.
\end{abstract}

Keywords: Challenges, Discrimination, Marginalisation, Narrative, Opportunities, PLWDs, South Africa, Symbolic Interactionism, Unemployment.

\section{BACKGROUND}

Throughout the world, the history of black people living with disabilities (PLWD) has been that of discriminated against by societies which resulted to segregation, banishment, infanticide, and genocide. The discrimination also results in the systematic underrepresentation of PLWD in key areas of social, economic and political life of any country. In various countries, PLWD are still prohibited from human rights benefits such as employment, permission to get married and land, opening a bank account, voting, having legal capacity, education, and the right to life. Studies found that the under-representation of minorities such as PLWD from the labour market is rife and is unswerving (Disability Rights Policy, 2015).

Despite marginalisation and discrimination, PLWD suffer from inferior health outcomes, poorer education achievements, with less economic participation and higher rates of unemployment that result in poverty than people without disabilities. In spite of discrimination, exclusion and marginalization, they are also disadvantaged people due to low socio-economic status (Ngwena, et al., 2017). Above all, PLWD are faced with extreme challenges in gaining access to housing and other basic services. Evidence shows that

*Address correspondence to this author at the University of Venda, South Africa; E-mail: rendani.tshifhumulo2@univen.ac.za it is unusual for indigenous PLWD to be property owners as they have no access to land. These people have been severely affected by lack of access to traditional lands and land-grabbing, which disrupts access to dignifying livelihoods, and prevents them from exercising their social and cultural rights. Access to land is measured as the main feature of indigeneity (native membership of an indigenous group). Information on accessing the land rights for indigenous PLWD is limited and scattered (International Labour Organisation (ILO), 2015). These are some of the disabling barriers that often restrict PLWD of participating in society on an equal basis with others an issue that causes them not to be seen in the public space. The disabling barriers also contribute to the disadvantages experienced by PLWD in all countries and which result in poorer health, lower education, and less economic participation, all leading to higher rates of poverty and increased dependency, restricted participation and exclusion (African Union Commission (AUC), 2010 - 2019).

In addition to the disabling barriers, there is unimplementation of legislative laws which are the main cause that impinges on PLWD's lives. The budgets which are under-spent and the lack of political will, have strictly discouraged efforts to secure socioeconomic rights for PLWD in South Africa, mainly in housing (Ebrahim \& Masiangoako, 2019). It is understood that there is limited understanding of 
disability by policy makers and service providers, that seems not to fully grasp that this is a human rights and development issue. Hence, this is crucial to the exclusion of PLWD from a comprehensive improvement of disability mainstreaming and disability policy, despite the political will to restore the inequity of the past the Disabled People South Africa (DPSA), (2013).

\section{LITERATURE REVIEW}

\section{Experiences of Unemployment among Disabled Adults}

The United Nations' (UN) Security Council acted universally to adopt resolution 2475, on June 20, 2019. It called upon member states and parties to protect PLWDs in conflict situations and to ensuring that they have access to justice, basic services and unimpeded humanitarian assistance. As there is still a long way to go to ensure the rights of PLWDs in Central African Republic (CAR), the situation remains precarious for PLWDs, although some progressive steps are being taken. These people are still not respected and protected both in times of conflict and in everyday life. At this point in time, the on-going violence and discrimination continue unaffected (Quy, 2019).

According to the world Report (2011) PLWDs are not taken seriously as a work force that could contribute to a country's economy, due to their disability and discrimination. This situation emanates from the social stigma that is associated with disability, poverty, marginalisation and social isolation (World Report, 2011). What is more, the stigma and poverty often compels them to become beggars in the streets as their only means of survival. This type of behaviour contradicts who they really had been before they were isolated by the system of social power, which was within society and later found in politics (Naami, 2015). In Africa, PLWDs have difficulties in acquiring basic needs such as health, housing, employment and education that can offer and empower them with knowledge and skills, specifically culturally orientated knowledge. These basic needs remain inaccessible to them and the deficiency in these basic needs affects their life chances, as they are the already marginalised group, with a double burden, disability and unemployment (Disability in Africa, 2012).

Most Africans with disabilities are unemployed and are regarded as the poorest of the poor through marginalisation (Naami, 2015). This virtually leaves them in poverty that continues without any interruption. As such, throughout Africa, PLWDs are perceived to be hopeless and helpless people, such that they are seen as weak people who are unable to perform any duties (Disability News Africa, 2016). In countries like the Central African Republic, PLWDs are not protected as it is perceived that they have been largely neglected in the humanitarian response to conflicts around the world. There have been calls all over the world to protect these people from conflict and to increase the humanitarian responses in addressing the needs of PLWDs (Quy, 2019). Data continues to be limited, despite recent improvements on a significant amount of PLWDs who work in the informal economy in many countries. As such, they do not appear in all labour market statistics nor are they covered by employment legislation. Research data from various countries show that the employment rates for PLWDs are below that of the overall population with the employment ratio varying from lows of $30 \%$ in South Africa and $38 \%$ in Japan to highs of $81 \%$ in Switzerland and $92 \%$ in Malawi (First Country Report, 2012). PLWDs are part of indigenous people. In the ILO of Indigenous and Tribal People's Convention 1989, it was said that the absence of access to acceptable protection is a reality for millions of indigenous peoples. This requires to be understood contrary to the context of their collective experiences of historical injustices, including colonisation and deprivation of their land, territories and resources as well as persevering marginalisation, while detailed data is unavailable (ILO, 2018).

\section{Unemployment among PLWDs in South Africa}

South Africa is generally a country that is ravaged by an unemployment crisis estimated to be to 6.1 million (27.2\%). Recently, this percentage of unemployment has risen to 29\% (Webster, 2019). Working-age black Africans, particularly those living with disabilities, are without work. The Commission for Employment Equity (CEE) in 2016 reported a slight progress in the employment of PLWDs, since the initiation of the Employment Equity Act (EEA) legislation in 1998 and the declaration of chapter 3 of this Act in 1999 (Stats SA, 2014). Unemployment, inequality and poverty have a serious impact on unemployed black Africans in general, (Keeton, 2014). These are voices of the marginalised: persons with disabilities, older people, people with mental health issues. PLWDs are faced by various hurdles in their struggle for equality as they experience hardships. Even though men and women with disabilities are exposed to discrimination due to their disabilities, 
women with disabilities are experiencing more disadvantages because of the collective discrimination which is based on gender and disability (ILO, 2015). PLWDs are frequently treated as asexual, genderless human beings. Yet, women with disabilities and men with disabilities differ in their life experiences due to biological, psychological, economic, social, political and cultural attributes that are associated with sex. Their weaknesses are regularly associated with variances in the social position of women and men. The exclusion of health and sanitation is appalling, as women with disabilities are less likely to receive health screenings than women without disabilities. They are also likely to receive less routine clinical preventive services to fend off or identify the onset of health conditions and illnesses such as cancer. This results into undiagnosed or unmanaged and even a delayed diagnosis having a greater consequence for recovery or cure (Fact Sheet, 2017).

Stats SA (2014) revealed that 2.9 million South Africans live with disabilities and eight in every ten PLWDs are unemployed. It is reported that $68 \%$ of adults living with disabilities in the country are not working and are not looking for work due to discrimination, as they know it is unlikely that they will be employed. Most of those who do find work are more likely to be employed under insecure and exploitative conditions (Maja et al., 2011). As such, they are inactive and powerless. In addition to this problem, several PLWDs who are employed are mostly employed to do tedious and unskilled tasks. They are likely to be insecurely employed and within a noisy environment and as such, most of them are hired at the lowest entry levels of the organisation (Fact Sheet, 2017).

Evidence has shown that South African employers are known to be reluctant in employing PLWDs, as they have no confidence in their capabilities. They argue that employing PLWDs is too costly. They accept that PLWDs appointments may create complications in the workplace which will acquire costs that will change the workplace atmosphere and make it inauspicious (UN Enable, 2011; Muja et al., 2011). Since skin colour in South Africa is something which matters most, black PLWDs carry the triple burden of being black, unemployed and disabled. As such, these people have no access to the labour market due to employers who are sceptical to employ those (Maja et al., 2011). Studies conducted by Gottlieb et al. (2010) on unemployment of PLWDs, voices of the marginalised: persons with disabilities, older people, and people with mental health issues revealed that, in societies, unemployed people are often excluded from important activities and social roles within the social group.

Men and women with disabilities often experience this exclusion because of being unemployed and particularly because of their disability, as people with disabilities are often discriminated against. Lately, the expectation for PLWDs was usually that of being unemployed. PLWDs with no qualifications are performing poorly in the labour market (Riddell et al., 2010) and their position has recently worsened in South Africa as the country's population is suffering from unemployment, particularly the youth and the disabled (Stats SA, 2014). The United Nations (2013b) reported a widening global gender employment gap which is persistent.Grimsha W, D., \& Rubery, J. (2015) argues that the global disability employment gap is evident in several other studies in the world. South Africa is not excluded from all the pproblems highlighted above experienced by PLWDs. Furthermore, $7.5 \%$ of South Africans are disabled (Stats SA, 2014). After having reviewed literature there is need to revisit the concerns/focus of the study so as to prepare yourself for the methodology section. Revisiting the main concerns of the paper is necessary because the research methodology selected is determined by the research problem. To understand experiences of unemployed this study used symbolic interactionist theory.

\section{The Symbolic Interactionist (SI) Theory}

The framework which was chosen for this inquiry is the Symbolic Interactionism (SI) Theory. The researchers' chose to use this framework because it is a sociological perspective that examines how individuals interact, focusing on the marginalised nature of unemployed black PLWDs through interaction with others (need for a reference here). SI is a microlevel theory that focuses on the relationships among individuals within a society. Through communication with each other, the interchange of meaning over language and symbols is believed to be the way in which PLWDs will make sense of their social worlds (Crossman, 2017).

The origins of the SI perspective are traced back to various influences from the mid-twentieth century, including Charles Sanders Peirce, John Dewey, Charles Horton Cooley, W.I. Thomas, George Herbert Mead, Erving Goffman and Herbert Blumer (reference is needed here as well). Herbert Blumer, (1969) 
introduced the term symbolic interactionism, with three core principles of this theory, namely meaning, language and thought (Crossman, 2015). These premises permitted social scientists who monitored the symbolic interactionism viewpoint to concentrate more on the human capabilities that they utilised for cultural purposes such as symbols, language and thought rather than relying on the existing truths, in order to comprehend the way in which persons or individuals are constructing their realities. Therefore, the capacity for individuals to use symbols enables individuals to be able to create meaning with regards to their own selves and to others who inhabit in the social world. Language allows people to communicate with each other to negotiate meanings, Thoughts, are responsible for individuals to be capacitated to reflect on symbols in modifying their interpretation through the thought process in order for individuals to enter the space of mental conversation (Davettian, 2018).

\section{METHODOLOGY}

Research on the plight of unemployed Black People Living with Disabilities is very scarce in South Africa. Therefore, the aim of this study was to examine the experiences of unemployed black men and women living with disabilities in South Africa to broaden existing knowledge on the conditions of marginalised groups as well as to inform and enhance the design of policy interventions aimed at alleviating the plight of PLWDs.
Data for this study were collected using semistructured interviews with 15 unemployed PLWDs between the ages of 24 to 35 in the Soshanguve Township. Snow ball was used to get respondents from the study. The study is part of the $\mathrm{PhD}$ and ethical clearance was sought from the University of Venda. Confidentiality, voluntary participation and reporting on findings are some of the ethics that were observed during the interaction with PLWDs. Data were analysed thematically by means of a narrative analysis with the intention of finding meaningful answers to the research questions and objectives and to disseminate the findings (McAlpine, 2016). Focus group in-depth interviews were conducted with unemployed respondents living with disabilities. The first focus group consisted of six (6) respondents of which four (4) were male and two (2) were female respondents. The second focus group consisted of nine (9) male and female respondents of which five (5) were male respondents and four (4) were female respondents. The focus group interviews were conducted in English at the SOSHAD centre.

\section{RESULTS}

The main themes which emerged from the study are challenges, opportunities and coping strategies for the unemployed people with disabilities. Table 1 below summarise the main challenges, opportunities and coping strategies adopted by Black South Africans living with disabilities.

Table 1: Challenges, Opportunities and Coping Strategies Adopted by Black South Africans Living with Disabilities

\begin{tabular}{|c|c|c|}
\hline THEME 1 & Sub-theme & Meaningful Units from the data \\
\hline Challenges & $\begin{array}{l}\text { Discrimination } \\
\text { Depression } \\
\text { Low self-esteem } \\
\text { Barriers of employment } \\
\text { Homelessness }\end{array}$ & $\begin{array}{l}\text { Unemployment } \\
\text { Exclusionary barriers } \\
\text { Employers' crookedness } \\
\text { Tendencies }\end{array}$ \\
\hline THEME 2 & Sub-theme & Meaningful Units from the data \\
\hline Opportunities & $\begin{array}{c}\text { Qualification } \\
\text { Socio-economic challenges } \\
\text { Lack of Resources } \\
\text { Social grants }\end{array}$ & $\begin{array}{c}\text { Lack of information } \\
\text { Discrimination by society }\end{array}$ \\
\hline THEME 3 & Sub-theme & Meaningful Units from the data \\
\hline Coping strategies & $\begin{array}{c}\text { Difficulty in coping } \\
\text { Social constraints and financial support } \\
\text { Job opportunities } \\
\text { Lack of income }\end{array}$ & Inadequate policies \\
\hline
\end{tabular}


The study revealed several challenges faced by unemployed Black PLWDs people living with disabilities in Soshanguve Township in post-apartheid South Africa. The main challenge revealed by this study is that most PLWDs lived for long periods without employment due to discrimination and marginalisation by employers. The irreparable damage caused by discrimination leaves them with concerns such as being labelled as incapacitated, inactive, poor, economically disadvantaged and homeless. There are two major challenges that they experience which are perceived to have had a great impact to them:

(a) The non-implementation of the EEA legislation Number 55 of 1998 that was meant to protect them and open doors for employment. The nonimplementation of this legislation caused them to be vulnerable to employers as they were not protected by legislation.

(b) The minimal support of social grant that was offered by Government and which was of little enough and other officials in the Labour Department uncouthness, crookedness and corrupt, Discrimination was an everyday experience at the workplace, so much so that assistance as it could not meet their financial and family needs since it was not most respondents were motivated to look for jobs and go back to work due to discrimination. Respondents were excluded when they applied for jobs and exclusion was one of the strategies used by employers to keep them unemployed. (Poverty (Elwan, 1999).

Respondents said,

"We have stopped looking for jobs due to discrimination even if we apply we are seldom called for interviews. If we go to check why we were not called for a long period, we were harassed by employers. If one is qualified is seen as someone who comes to change the environment of the workplace. These were some of the barriers that affect PLWD in their daily lives. Even if you try to be self-employed there will be an issue of not getting a capital to start-up the business"

"When I asked for employment to a certain company, the employer looking at my disability said, it would be very expensive to change the whole setup in the workplace only for me and also my hand will need a lot of adjustments in the computer"

"Employers should realize that special
accommodations were not an
inconvenience, but it adds to the value
and improves efficiency. It is no different
than adding a step stool in your kitchen to
help you reach the top shelf. We all need
'accommodations' at some point, even the
able-bodied"

Upon seeking for job opportunities, respondents viewed employers as uncouth, crooked, corrupt and unfaithful to towards them. They deduced that employers and other officials in the labour department asked respondents to pay money to get a job, knowing fully well that they were unemployed and poor. Alternatively, respondents would be given an option to allow employers to deduct R1000.00 from their salaries every month. Furthermore, employers used the names of respondents who have applied for tenders in the Department of Labour to obtain tenders through them. Respondents argued that, when they applied for tenders themselves, the exercise was futile. Respondents said,

"Employers were crooked when it comes to disability. They asked to be paid when you ask for a job and they know we don't have money as we are unemployed and poor. When they employ us, we were working on contract positions, never on a permanent positions because we are sick but the disabled whites were on permanent positions. They make you to sign forms every year for four years without any permanent employment. The government is crooked when it comes to disabled people"

"I struggled myself to get a job and to get educated to be where I am today. Right now I cannot be taken anywhere to do a job as I'm blind. It's even worse when you are young and disabled. When you are accepted, they put you on a contract for years signing forms every year until you are told the forms are frozen, you can't sign anymore form. You will know the contract has finished" 
In addition, respondents mentioned that employers were ignorant about disability and had lack of understanding their condition. Transportation was also mentioned as a problem. Public transport was not easily accessible and was too costly with far-reaching social and economic consequences such as paying for going from place to place, for accompaniment, for children to school and health centre and hospital appointments.

"The government and employers also feel strange about us. They think something is wrong somewhere in our thinking and never taken us seriously and yet our minds and eyes are healthy and are aware of what is going on around us. So we struggle in life to get work. It's easy for a working person to say they understand our situation but you see they don't understand the way we do and we suffer as they always want to find the reasons why we are not employed and staying at home"

"The thing is with the employers they don't want to understand us. They always have that fear about our dressing style and I always find it strange to be asked about our wearing jerseys and coats even when it's hot. It's not that we choose wearing them, our bodies always feel cold. It's according to our injury levels that make us feel cold all the time. It's different to them because they are mobile and we are stagnant and confined to wheelchairs. This is depressing"

Another great barrier was transportation to the workplace, to meetings and to health centres where respondents had to be on time. Public transport is said to be disordered and the taxi system not well organised. Accessing the taxi ranks was viewed as a huge problem and getting into the taxi with a wheelchair or crutches only added to the problem.

Visible inaccessible environments in the township made it difficult to manage wheelchairs due to ragged, rough and irregular roads. There was less freedom of movement where there were no tarred roads. In the shopping centres, there were no off-ramps for driving wheelchairs. Inaccessible public buildings with no lifts and those relating to communication including lack of information in accessible formats (Cain, 2012).
"Living in Townships where there are no tarred roads and driving wheelchairs is a problem as there is no freedom of movement for us. Taxi system is not running very well and the public transport is a big problem we are facing on daily basis. Reaching taxi ranks is a problem and getting to the actual taxi with a wheelchair is another problem"

"We are at the mercy of taxi drivers who are insensible and always shouting at us all the time. They do not stop for us on the road, sometimes they will just pass you even at the taxi rank. They say we are making them to lose money by walking slow. If you happen to enter, there is no decency, as you are trying to fix the chair and making yourself comfortable, the taxi is already moving. If you are driving a wheelchair, they say you have to pay for it as you taking or blocking someone else's space"

Respondents also mentioned the issue of homelessness. They failed to get hold of their own RDP houses despite applying for houses and/or land to build their own houses and grow food from Government. They felt that social exclusion from political and economic processes was contributing to the cycle of poverty (Elwan, 199).

"We don't have land of our own and we don't own houses. We rent rooms at the backyards of peoples' houses while others live in the squatter camps and others with friends. The only option is for the government to build us houses or us or give us land to tilt and grow food. Living in the township and in squatter camps is scary as you are never safe"

"Accommodation is a problem. We have been applying for houses. The government refuses to give us accommodation. They build houses for non-disabled people. Some of us are living with friends as we are rejected by our families because of our disability. We live in Mikhukhu with our families as we don't have houses and it becomes a problem when it rains." 
"I live with my children in an Mkhukhu, I have no husband. I've got nowhere to go. This is my home. When it's raining we go and look for a shelter. I do peace jobs in these houses during the day, but now I have to come to a Learner ship Programme to upgrade myself. It's not easy because we pay for ourselves in these programmes as we are not employed, but we support each other"

\section{Opportunities}

Respondents argued that there were no job opportunities in the township and lack of projects in place from Government to alleviate poverty and keep them out of isolation was highlighted.

"Unemployment is a big challenge to us in this country and is even worse in Soshanguve. It's a stress to be unemployed, not to work being a man and disabled and having no money, because people need money and they don't have".

Poverty was mentioned as a burning issue mentioned that required urgent address among PLWDs due to unemployment and lack of business projects. Poverty was affecting their health status, particularly the health of women until some women developed survival skills like selling vegetables, fruits, sweets and chips in the streets to get an income, although not much and which depended on the weather conditions. These people had limited chances of getting access to social protection mechanisms and social networks of support. Government social grants were said to be the only means of survival but were not enough to solve the family's financial needs. Entering the job market after leaving education can prove 'to be a tough challenge for anyone in today's climate. However, respondents with disabilities faced far less options for employment than non-disabled candidates. Some respondents mentioned that lack of education was also standing in their way to get employment. The Department of Labour (DOL) which has been given authority to manage, monitor and get committed to comprehensive employment practices, as stated in several pieces of legislation and policies, is fragmented President Ramaphosa acknowledged that South Africa's progress on women empowerment has been uneven (South African News Agency, 2019) (Policy Brief, 2013-2017). Hence, it could not give much assistance to respondents. The Department of Labour is not transformed and it is still practicing discriminatory actions from the legacy of the apartheid laws that have been continuously closing the doors for employment opportunities for PLWDs. The respondents' participation in the market economy was alleged to be very low. We need interview data (quotations) to support the points

\section{Difficulty in Coping}

Respondents felt depressed by being disregarded by government. They expressed their feelings of unhappiness and rejection. Where is the evidence?? They felt they had exhausted all the resources, i.e. making an income by opening small businesses that were warped off with no backing as nothing seemed to be operational. Respondents were not coping with the situation of unemployment and poverty as they could not manage their families. They utilised whatever coping mechanisms they had to handle the stress. They felt defeated and showed feelings of anger and resentment. They felt that lack of a support system was fatal as it affected their health status since President Ramaphosa acknowledged that South Africa's progress on women empowerment has been uneven (South African News Agency, 2019). Women had no income and the previous efforts to eradicate poverty and inequality had been overlooked (Hanass-Hancock \& McKenzie, 2017). They believed that there was nothing else that they could do as no one could rescue them from this misery, except for drastic economic measures that be taken by Government to change the situation. Where is the evidence from the interviews?

Respondents with limited social grant had nowhere to turn to for more financial support, except to their families. This implied that many PLWDs were are reliant on social benefits as a source of income (Alcock, 1999). They did not see social grants as a reliable source of income. Even trading President Ramaphosa acknowledged that South Africa's progress on women empowerment has been uneven (South African News Agency, 2019). in the streets did not bring much income. Respondents claimed that the future was bleak and not promising since there and economic decline in the country. They did not anticipate a bright future for them since there were no opportunities coming their way during this period of economic decline. We need interview data here to support the arguments. Did the respondents say this? If so where is the evidence from the transcripts?

Respondents' felt dishonoured by the inadequate policies, including the actions of the labour laws. The 
non-implementation of the EEA legislation No 55 of 1998 undermined them as human beings as it encouraged employers to practice discrimination and attitudes against them knowing that there would not be any accountability as they were not protected by the act. They blamed the insufficiency of government regulations and policies that were incomplete and some un-implemented. This irresponsibility was shown by SASA and Labour Departments for not caring for them. The underrepresentation of PLWDs in the critical domains of social, economic and political life also undermined them (Disability Rights Policy, 2015) and other officials in the Labour Department uncouthness, crookedness and corrupt; however, translating these rights into reality remains a challenge. There should be some excerpts from the interview data. I have not seen a single excerpt from the interviews. Simply summarising the views of the respondents is not enough.

\section{CONCLUDING REMARKS}

The aim of this study was to explore experiences of unemployed black men and women living with disabilities in Shoshanguve. The study revealed that black unemployed PLWDs experienced difficulties in the Soshanguwe Township where they lacked employment opportunities and lived in poverty. Respondents were struggling to get to higher education even though some of them had matric certificates. The study reveals lack of projects by Government to alleviate poverty and to keep PLWDs from isolation. They had no income and felt that the policy of affirmative action was good but they were not meeting the targets. Respondents experienced discrimination at work and even if they are looking for jobs. They lost interest in job-seeking and did not look for work due to discrimination. The long periods of joblessness affected them and their families. Data revealed that various industries did not include PLWDs in their workplace. Different policies and employers remain in contempt by expressing unwillingness to hire these persons (The African Disability Rights Yearbook, 2014). PLWDs feel stressed due to discrimination, exclusion, negative attitudes and stigmatisation in the workplace. Employed PLWD mention that they were shouted at, degraded and stigmatised using strong words by employers, colleagues and staff members for many reasons at work. Disability bias affected them severely as they saw a negative impact on the way life systematised against them. Employers' were not accepted by the respondents. Respondents did not have formal qualification and they experienced difficulties in getting jobs since they missed opportunities. The Labour Department could get them into the system to be ready for learnership programmes to get skills which would enable them to be employable. In the conclusion you do not introduce new ideas.

Dependence on social grants as means of survival was viewed as bad tendency. Social grants were not considered as a reliable income. Female respondents remained poor and isolated compared to men with disabilities as they were frequently unemployed and were managing family chores. If employed, they earned far less than men. Poverty was viewed as a scorching matter that infringed the benefits of PLWDs in the Soshanguve Township and needed to be addressed urgently as they stressed due to discrimination, exclusion, negative attitudes and stigmatisation in the workplace. All respondents were not coping with the state of unemployment and poverty as they exploited any kind of coping mechanisms in vain in order to handle the stress. They were overpowered by the feelings of hopelessness and helplessness that were shown by antagonism and grieved. They perceived lack of a support system as fatal as it affected their health status since there was no income from the time that the previous efforts to eradicate poverty and inequality had been overlooked (Hanass-Hancock \& McKenzie, 2017).

This study examined the experiences of unemployed black people with disabilities in the Soshanguve Township, South Africa. The article provides a starting point of analysis of the scope that PLWDs are faced with on their daily basis. The research focused on exposing the important activities that PLWDs were involved with in their communities in the post-apartheid era which were not building their livelihood. For the purposes of the study, the theory and methodology applied were relevant as they provided guidance on the interpretation of the main findings. The theory also explained what the researchers were expectant of e.g. the various interpretations regarding different thoughts and ideas on how society mismanaged PLWDs. The SI theory contributed towards clarifying aspects that define the social conditions of the township in which PLWDs live and the routine of their existence (Crossman, 2016). In recognition that disability as a growing concept emanates from the interaction between PLWDs and impairments, it also results from attitudes and environment barriers that obstruct their full and effective contribution in society on an equal basis 
with others. It is crucial to understand that disability is a grave issue that needs care and support.

\section{REFERENCES}

Alcock, P. 1999. $2^{\text {nd }}$ ed. Understanding Poverty. (second edition). London: Macmillan, Cain, E.

Crossman, A. 2016. The Principle of Symbolic Interactionism Essay. Bartleby Research. https://www.bartleby.com/essay/ThePrinciple-Of-Symbolic-Interactionism-FKB9DB5Y9JXW [Accessed: 24 September 2019].

Davian, B. Edited by: Albert J. Mills, Gabrielle Durepos \& Elden Wiebe, Book Title: Encyclopedia of Case Study Research. Chapter Title: "Symbolic Interactionism" Thousand Oaks. SAGE Publications, Inc. City.

Disability in Africa 2014. African Studies Centre, Laden. Website: https://www.disabled- world.com/ news/Africa/ [Accessed 14 January 2015]

Disability Rights Policy of Gauteng Provincial Government 2015. "Nothing about Us without Us". South African Government Hotline: 08604288364 Website: www.gautengonline.gov.za [Accessed, 12 February 2017]

Gottlieb, A., Mayhill, W. \& Blank, P 2010. Employment of People with disabilities International. Website: https://www.academic.edu/ 51631 [28 April 2018]

Encyclopaedia of Rehabilitation, Eve Hill, Peter Blank, 2009. Future of Disability Rights in Americans: part Three Statues of Limitation in Americans with Disability Act... [Accessed, 20 May 2014]

Grech, S. 2016. Disability and Development: Critical connections, gaps and contradictions. Website: [Accessed, 24 April, 2019]. -related social protection measures in South Africa: Where is the gap? African Journal of Disability. https://doi.org/10.1007/978-3-319-42488-0 1

Keeton, G. 2014. Inequality in South Africa. The Journal of the Helen Suzman Foundation, 7(4). hsf.org.za/resource-centre/focus/ state...inequalityinsouth-africa...keeton.../download [Accessed: 24 May 2014]

Kock E., Molteno C., Mfiki N., Kidd M., Ali A., King M. 2012. Crosscultural validation of a measure of felt stigma in people with intellectual disabilities. 25(1), 11-19. https://doi.org/10.1111/j.1468-3148.2011.00644.x

Maja, PA., Mann, WM., Sing, D. Steyn, A.J. \& Naidoo, P. 2011. Employing PLWDs in South Africa. South African Journal of Occupational Therapy, 41(1)

Marshall, C. \& Rossman, G. B. 2011. Primary data collection methods designing qualitative research. Los Angeles, CA: SAGE.

McAlpine, L., 2016. Why might you use narrative methodology? A story about narrative. Oxford: University of Oxford, Department of Education. https://doi.org/10.12697/eha.2016.4.1.02b

Munyi, C. 2012. Past and present perceptions towards disability: a historical perspective. Disability studies Quarterly, the first journal in the field of Disability studies, 32(2). https://doi.org/10.18061/dsq.v32i2.3197
Naami, A. 2015. Disability, gender and employment relations in Africa: The case of Ghana. African Journal of Disability; 4(No. 1): Pages? (2015), 11 pages. https://doi.org/10.4102/ajod.v4i1.95

Patel, D.P. 2013. Research methods in social sciences. Website: http://hwa.org.sg/wpcontent/uploads/2017/09/HWA\%20Annu al\%20Report\%202017.pdf [Accessed: 04 April 2016].

Quy, B. 219. People with disabilities face widespread violence and discrimination in the Central African Republic. Global Citizen, Oct. 17. https://www.globalcitizen.org/en/content/disabilitiesin-central-african-republic/ [Accessed: 02 May 2020].

Riddell, S., Edward, S., Weedon, E. \& Ahlgren, L. 2010. Disability skills and employment: A review of recent statistic and literature on politics an initiative. Edinburgh: Centre for Research in Education, Inclusion and Diversity, University of Edinburgh. https://www.equalityhumanrights.com/... research-report-59-disability-skills- and employment [Accessed: 29 April 2013]

South African Government. 2012. Draft First Country Report to the United Nations on the implementation of the Convention on the Rights of Persons with Disabilities (CRPD) Website: DisabilityRights@dwcpd.gov.za. [13 September 2016]

South African News Agency. Acceptance statement for President Ramaphosa of the $2020 \mathrm{AU}$ leadership at the $33^{\text {rd }}$ Ordinary Session of the Assembly of Heads of State and Government in Addis.

Sudtho, J. Singhasiri, W. Zill, J. 2015. Using symbolic interactionism to investigate teachers' professional identity. Website: https://www.researchgate.net/publication/285219264_Using _symbolic_interactionism_to_investigate_teachers'_professio nal_identity

Stats SA (Statistics South Africa) Consensus. 2011. Profile of persons with disabilities in South Africa. Pretoria: Statistics South Africa. www.statssa.gov.za/?page_id=3839 [Accessed: 15 November 2014].

Stats SA (Statistics South Africa). 2013The Dynamics of Labour Department (QES). www.statssa.gov.za/? $p=2804$ [Accessed: 24 August 2015]

Stats SA (Statistics South Africa). 2014. The March 2014 quarterly employment statistics (QES). Stats SA, Pretoria.

Thorne, S. 2018. Data analysis in qualitative research. [Accessed: 09 April 2018]. https://doi.org/10.1136/ebn.3.3.68

UN (United Nations) Convention on Rights of Persons with Disabilities. UN Enable. 2011. Development and human rights for all. Factsheet 2 on Persons with Disabilities. https://www.un.org/development/... disabilities/ [Accessed: 15 February 2016].

Webster, D. 2019. Unemployment in South Africa is worse than you think. Mail \& Guardian, 05 August.

WHO (World Health Organization). 2011. World report on people with disabilities. www.who.int/disabilities/world report/2011/report [Accessed: 08 June 2016].

https://doi.org/10.6000/1929-4409.2021.10.183

(C) 2021 Jobodwana and Tshifhumulo; Licensee Lifescience Global.

This is an open access article licensed under the terms of the Creative Commons Attribution License (http://creativecommons.org/licenses/by/4.0/) which permits unrestricted use, distribution and reproduction in any medium, provided the work is properly cited. 